\title{
Current status of periodontitis and its association with tobacco use amongst adult population of Sunsari district, in Nepal
}

\author{
K. Goel ${ }^{1^{*}}\left(\mathbb{0}\right.$, S. Sharma ${ }^{1}$, D. D. Baral ${ }^{2}$ and S. K. Agrawal ${ }^{3}$
}

\begin{abstract}
Background: Tobacco products are considered significant, but preventable factors related to initiation and progression of periodontal diseases. We assessed the prevalence of periodontitis and evaluated its association with tobacco use and other factors amongst the adult population of Sunsari district in eastern Nepal.

Methods: A community-based, cross-sectional study was conducted in rural municipalities in the province one of eastern Nepal. A total of 440 adults were interviewed with a set of a pre-tested semi-structured questionnaire. Data on social demographics, adverse oral habits followed by periodontal clinical examination were recorded. Prevalence of periodontitis was assessed by a case definition provided by CDC-AAP. Univariate and multivariate logistic regression analysis was done to measure the association between tobacco use and other factors with periodontitis.

Results: The overall prevalence of periodontitis was found to be $71.6 \%$. Majority (85.4\%) of tobacco users had periodontitis and they were significantly associated with the disease and its severity. The study identified age groups, 45-65 years ( $\mathrm{AOR}=7.58,95 \% \mathrm{Cl} 3.93-14.61$ ), plaque accumulation ( $\mathrm{AOR}=1.01,95 \% \mathrm{Cl} 1.00-1.02)$, smoking $(\mathrm{AOR}=3.14,95 \% \mathrm{Cl} 1.36-7.27)$, khaini users (smokeless tobacco, $\mathrm{AOR}=2.27,95 \% \mathrm{Cl} 1.12-4.61)$ and teeth loss $(A O R=2.02,95 \% \mathrm{Cl} 1.21-3.38)$ as the significant factors associated with periodontitis.

Conclusion: The prevalence of periodontitis is high in the surveyed rural adult population. Cigarette smoking along with the use of smokeless tobacco in the form of khaini were identified as significant factors associated with periodontitis.
\end{abstract}

Keywords: Periodontitis, Prevalence, Smoking, Smokeless tobacco

\section{Background}

Periodontal diseases are a result of a disruption in the host microbial interaction, and are known to be one of the major causes of tooth loss [1]. Overall, this disease affects about $20-50 \%$ of the global population [2] and in its severe form, ranks sixth among the most prevalent disorders [3]. Although dental plaque-associated

\footnotetext{
*Correspondence: khushboo.goel@bpkihs.edu

${ }^{1}$ Department of Periodontology and Oral Implantology, College of Dental Surgery, B.P Koirala Institute of Health and Sciences, Dharan 56700, Nepal

Full list of author information is available at the end of the article
}

microorganism are the primary etiologic agent, several other factors such as genetic, systemic, immunological, environmental and behavioral factors play an important role in determining the susceptibility of individuals to periodontal diseases $[4,5]$.

Among the environmental factors, tobacco smoking is considered one of the true risk factors and is known to be independently related to periodontal destruction [6]. The common forms of tobacco smoking are cigarette, beedi, chutta and hooka, with cigarettes being the main product smoked [7]. More than seven thousand toxins are present in tobacco smoke [8] including, carcinogens and addictive psycho-active substances like nicotine, 
which are detrimental to general health and also a major public health concern [9]. In addition, the use of smokeless tobacco (SLT) as an alternative tobacco product to cigarette smoking is gradually becoming popular. An estimated 346 million people in the world use SLT products and the prevalence of use is relatively high in Southeast Asian region accounting for nearly $86 \%$ of the global users [10].

SLT is consumed un-burnt and exists in numerous forms across the globe with various applications, e.g. in the USA, SLT is available in the form of chewing and snuff (moist and dry) and in Sweden it is available as snus [11]. In South East Asian countries, most commonly available and used SLT products is "khaini" (powdered tobacco/leaves with slaked lime paste) that is placed in the mouth for use or held between the gum and cheeks for a varied amount of time. Other products that are ingested through the oral tissues, chewed or swallowed [12] are betel quid with or without tobacco like zarda (boiled tobacco leaves with water and slaked lime) and gutkha (areca nut with added tobacco, slaked lime and catechu) $[11,13]$. Unlike tobacco smoke that is a risk for overall periodontitis, reports suggest smokeless tobacco products have a greater clinical attachment loss (CAL) only near the area where the products are placed in the mouth [14]. However, conclusion vary when the loss of interproximal bone is discussed. Few studies corroborate the association between SLT use and bone loss [15] but it is not in agreement with others $[14,16]$. SLT use and generalized periodontitis is also, a debatable issue as the use is not necessarily associated with overall periodontitis.

Early evidence has given an indication that the Nepalese population is highly susceptible to periodontitis and other oral health related problems [17]. The rising cost of dental services and lack of proper oral hygiene practices contributes to poor oral health status in Nepal. In addition, smoking habits as well as consumption of smokeless tobacco which are common and prevalent in Nepal [18], further contribute to the oral health related problems. Hence, identification of socio-demographic factors, habits and disease prevalence becomes crucial to take action, promote and implement oral health interventions in rural and urban areas. The aims of this study is therefore, to assess the prevalence of periodontitis and to evaluate its association with tobacco use and other factors among the adult population of eastern Nepal.

\section{Methods}

A cross-sectional study was carried over a period from April 2018 to July 2019 with the approval of the Institutional Review Committee of B.P Koirala Institute of Health Sciences, Dharan, Nepal. The principles of the Declaration of Helsinki were followed during this study.
The study obtained written consent from each participant after explaining the objectives, and use of the study. The population involved in this study were inhabitants from the rural area of Sunsari district, in the eastern region of Nepal. Sunsari district comprises of twelve, both rural and urban municipalities. Dental health camps were organized in different wards of six rural municipalities (Koshi, Gadhi, Barju, Bhokraha, Harinagara, Dewanganj) by Department of Public Health Dentistry. The study selected one ward, in each of the six rural municipalities, based on a lottery method. The total eligible population of these wards was approximately 16,120 (estimated population between the age of 20-65 years) [19]. Approximately 1578 inhabitants, who attended the dental health camps were registered in the camp register list, and two out of every seven registered participants were selected in a random manner and examined. Among them a total of 440 participants who met the inclusion criteria were interviewed and enrolled in the study (Fig. 1).

\section{Criteria for selection: inclusion criteria}

Patients between 20 and 65 years old, tobacco users who were currently consuming tobacco in the form of smoking or smokeless tobacco, non-tobacco users who had never used tobacco in any form (smoke or smokeless tobacco), and patient who consented for clinical examination and answered the comprehensive questionnaire.

\section{Exclusion criteria}

Former smokers, patients who actively consume alcohol, patients suffering from known systemic illness, pregnant and lactating females.

\section{Method of data collection}

A set of pre-tested semi- structured questionnaire was prepared and face-to-face interviews in local language were conducted to record the data on social demographics, adverse oral habits and oral hygiene status. The questionnaire is available as the Additional file 1. Age groups were categorized into three categories, as "20-34", "35-44", "45-65" years and Body Mass Index (BMI) was calculated as body weight $(\mathrm{kg})$ divided by height $\left(\mathrm{m}^{2}\right)$. Socio-economic status was assessed and categorized into upper, lower middle and lower class [20]. To ensure objectivity, direct questions were asked to the participants regarding their use of tobacco. Current smokers were defined as subjects smoking more than five cigarettes per day for the past 2 years or more, and subjects consuming smokeless tobacco on a daily basis for the past 2 years or more [21].

The SLT users were dichotomized as participants who consumed khaini and those who chewed SLT (gutkha, betel quid with tobacco, zarda). Intraorally, Plaque 


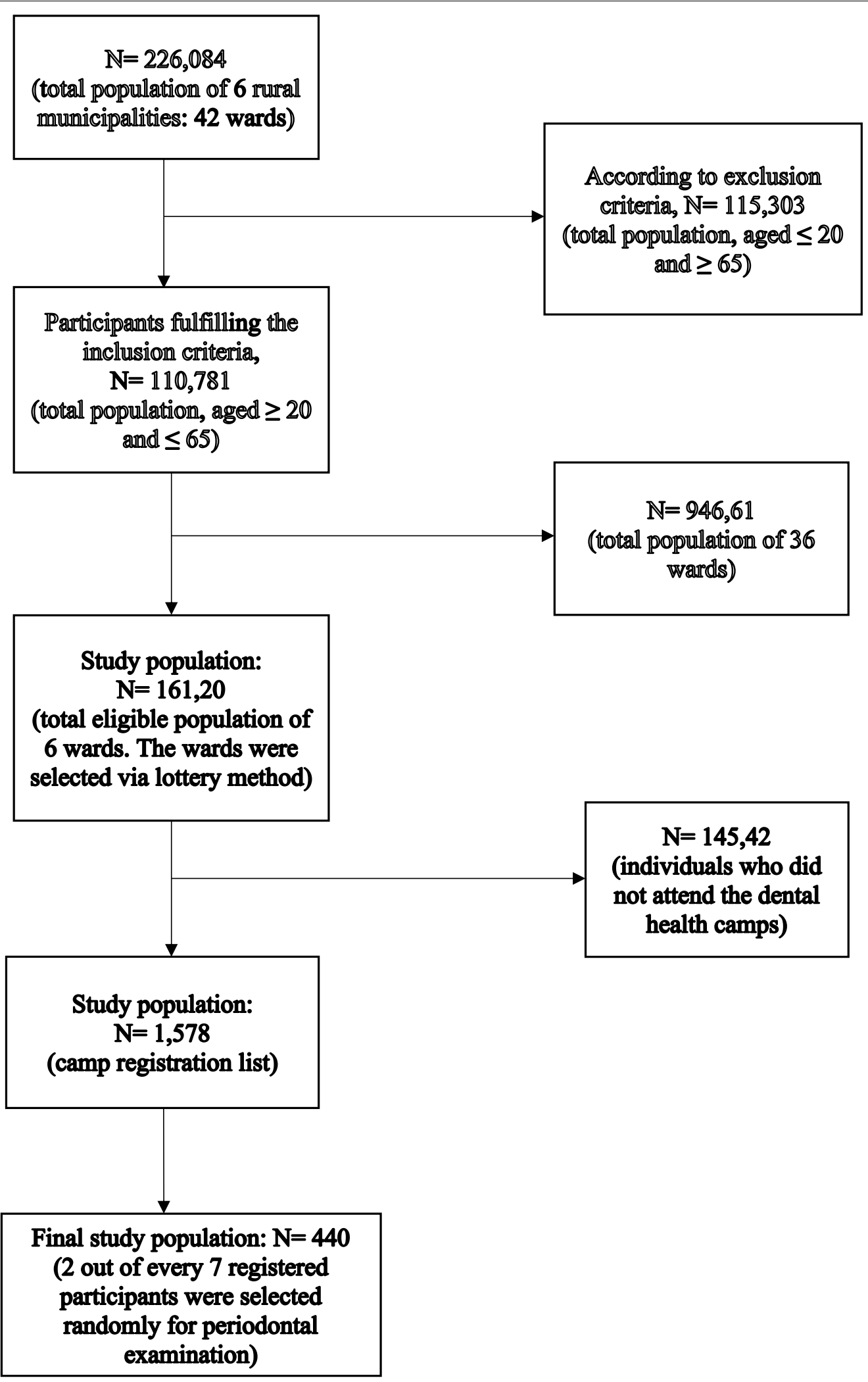

Fig. 1 Flow diagram of participants 
Index (PLI) was recorded as the presence or absence of visible plaque [22]. Bleeding Point Index (BPI) was used to examine presence or absence of bleeding on probing [23]. Simplified Oral Hygiene Index (OHI$\mathrm{S})$ was recorded according to Greene and Vermillion, 1964 [24]. A periodontal probe, UNC-15 (University of North Carolina-15, Hu-Friedy, Chicago, IL) was used for all periodontal recordings. To avoid inter-observer variation, a single experienced periodontist (K.G) examined all subjects and the dental hygienist (K.T) was trained by the researcher to fill the questionnaire form. The kappa statistics was assessed among the fortyfour participants who were not enrolled in the study. The participants were re-examined after one week of first examination and the value averaged 0.8 for intraexaminer reliability. The prevalence of periodontitis in this study was estimated based on the case- definition given by CDC-AAP in 2012 [25]. Absence of periodontitis was defined as, no indication of mild, moderate, or severe periodontitis. Mild periodontitis: two or more interproximal sites with CAL of $\geq 3 \mathrm{~mm}$, and $\geq 2$ interproximal sites with Probing Depth (PD) $\geq 4 \mathrm{~mm}$ (not on same tooth) or one site with $\mathrm{PD} \geq 5 \mathrm{~mm}$. Moderate periodontitis: two or more interproximal sites with CAL of $\geq 4 \mathrm{~mm}$ (not on same tooth), or $\geq 2$ sites with $\mathrm{PD} \geq 5 \mathrm{~mm}$ (not on same tooth). Severe periodontitis: two or more interproximal sites with CAL of $\geq 6 \mathrm{~mm}$ (not on same tooth) and $\geq 1$ site with $\mathrm{PD} \geq 5 \mathrm{~mm}$ [25]. PD was measured to the nearest millimeter as the distance from the gingival margin to the bottom of the periodontal sulcus/pocket (cut-offs at $\geq 4 \mathrm{~mm}$ and $\geq 5 \mathrm{~mm}$ ). CAL was computed from the CementoEnamel Junction (CEJ) to the base of pocket/sulcus (cut-offs at $\geq 3 \mathrm{~mm}, \geq 4$ and $\geq 6 \mathrm{~mm}$ ). Presence of caries was examined with a dental explorer, teeth loss and the reason for each tooth loss as self-reported by the participants were recorded.

\section{Statistical analysis}

Descriptive statistics, mean, standard deviation, percentage and frequency were calculated for all the variables along with tabular presentations. Univariate and forward conditional method for multivariate logistic regression was done to assess the crude and adjusted odds ratio with $95 \% \mathrm{CI}$ to find out the association between tobacco use and other factors with periodontitis. Level of significance was set at $p<0.05$. Those variables that fell under $p<0.2$ at univariate analysis, were considered for multivariate logistic regression. All the data collected data was entered into Microsoft Excel 2007 and converted using the statistical software package SPSS 11.5 (SPSS, Chicago, IL, USA) for further analysis.

\section{Results}

A total of 440 participants with the mean (SD) age of 43.80 (13.17), comprising of $42.3 \%$ males and $57.7 \%$ females were analyzed in the study. Periodontitis was found to be present in $71.6 \%(n=315)$ of surveyed populations. The average BMI of participants was $24.18 \pm 2.74$ with the mean PLI score $67.82 \pm 21.83$ and median BPI with IQR (min-max) score of 43 (23-65) (5-100). The 57 participants who had lost their teeth due to periodontal disease (TLPD), all had some form of periodontitis in their remaining teeth with $57.9 \%$ having severe, 33.3\% moderate and $8.8 \%$ having a mild form of periodontitis. Dental caries were present in $63 \%$ of the adults examined. Nearly one in every two individual aged 21-65 years (46.6\%) were found to be using some form of tobacco (Table 1).

(Table 2) The prevalence of periodontitis and its severity were significantly associated with age.

\section{Table 1 Characteristics of study population $(n=440)$}

\begin{tabular}{|c|c|c|}
\hline Variables & Subcategory & Frequency (\%) \\
\hline \multirow[t]{3}{*}{ Age groups } & $20-34$ & $110(25.0)$ \\
\hline & $35-44$ & $124(28.2)$ \\
\hline & $45-65$ & $206(46.8)$ \\
\hline \multirow[t]{2}{*}{ Gender } & Females & $254(57.7)$ \\
\hline & Males & $186(42.3)$ \\
\hline \multirow[t]{3}{*}{ SES } & Upper class & $16(3.6)$ \\
\hline & Lower middle & $166(37.7)$ \\
\hline & Lower & $258(58.6)$ \\
\hline \multirow[t]{2}{*}{ Brushing frequency } & $\leq$ Once/day & $312(70.9)$ \\
\hline & $\geq$ Twice/day & $128(29.1)$ \\
\hline \multirow[t]{2}{*}{ Tobacco users } & Yes & $205(46.6)$ \\
\hline & No & $234(53.2)$ \\
\hline \multirow[t]{2}{*}{ Smoking status } & $\begin{array}{l}\text { Current smokers/Bidi } \\
\text { smokers }\end{array}$ & $91(20.7)$ \\
\hline & Non smokers & $349(79.3)$ \\
\hline \multirow[t]{4}{*}{ Smokeless tobacco (SLT) } & Users & $152(34.5)$ \\
\hline & Non users & $288(65.5)$ \\
\hline & Khaini users & $101(66.4)$ \\
\hline & SLT chewers & $51(33.6)$ \\
\hline \multirow[t]{3}{*}{$\mathrm{OHI}-\mathrm{S}$} & Good & $67(15.2)$ \\
\hline & Fair & $202(45.9)$ \\
\hline & Poor & $171(38.9)$ \\
\hline Teeth loss & Present & $218(49.5)$ \\
\hline \multirow[t]{3}{*}{ Reason for teeth loss } & Caries & $115(52.7)$ \\
\hline & Periodontitis & $57(26.1)$ \\
\hline & Others & $46(21.1)$ \\
\hline \multirow[t]{2}{*}{ Periodontitis } & Present & $315(71.6)$ \\
\hline & Absent & $125(28.4)$ \\
\hline
\end{tabular}

a Column percentage 
Table 2 Distribution of periodontitis and its severity according to age (CDC-AAP case definition) [25]

\begin{tabular}{lccccc}
\hline Periodontitis & \multicolumn{2}{l}{ Age groups (\%) } & \multicolumn{1}{l}{ Total } & $\boldsymbol{p}$ value \\
\cline { 2 - 4 } & $\mathbf{2 0 - \mathbf { 4 }}$ & $\mathbf{3 5 - 4 4}$ & $\mathbf{4 5 - 6 5}$ & & \\
\hline Present & $47(42.7)$ & $80(64.5)$ & $188(91.3)$ & $315(71.6)$ & $<0.001$ \\
Absent & $63(57.3)$ & $44(35.5)$ & $18(8.7)$ & $125(28.4)$ & \\
Total & $110(100)$ & $124(100)$ & $206(100)$ & $440(100)$ & \\
Severity of periodontitis & & & & \\
$\quad$ Mild & $38(80.9)$ & $23(28.8)$ & $42(22.3)$ & $103(32.7)$ & $<0.001$ \\
Moderate & $6(12.8)$ & $45(56.2)$ & $61(32.4)$ & $112(35.6)$ & \\
Severe & $3(6.4)$ & $12(15.0)$ & $85(45.2)$ & $100(31.7)$ & \\
Total & $47(100)$ & $80(100)$ & $188(100)$ & $315(100)$ & \\
\hline
\end{tabular}

Table 3 Association of periodontitis and its severity amongst the tobacco users

\begin{tabular}{lcrrr}
\hline Periodontitis & Tobacco users (\%) & $\begin{array}{l}\text { Non- } \\
\text { tobacco } \\
\text { users (\%) }\end{array}$ & Total (\%) & $\boldsymbol{p}$ value \\
\hline Present & $175(85.4)$ & $140(59.6)$ & $315(71.6)$ & $<0.001$ \\
Absent & $30(14.6)$ & $95(40.4)$ & $125(28.4)$ & \\
Total & $205(100)$ & $235(100)$ & $440(100)$ & \\
Severity of periodontitis & $35(20.0)$ & $68(48.6)$ & $103(32.7)$ & $<0.001$ \\
Mild & $62(35.4)$ & $50(35.7)$ & $112(35.6)$ & \\
Moderate & $78(44.6)$ & $22(15.7)$ & $100(31.7)$ & \\
Severe & $175(100)$ & $140(100)$ & $315(100)$ & \\
Total & & &
\end{tabular}

Mild, moderate and severe periodontitis was present in $32.7 \%, 35.6 \%$ and $31.7 \%$ respectively in the surveyed population. The $\mathrm{PD} \geq 4 \mathrm{~mm}$ were present in 181 (57.5\%) sites and $\geq 5 \mathrm{~mm}$ in 111 (35.2\%) sites amongst the periodontitis patients. A total of $26.3 \%$ of the population were affected with deep PD in 35-44 years age group that increased to $43.6 \%$ in $45-65$ years age group.

Tobacco users were significantly associated with periodontitis and its severity $(p<0.001)$.

Among tobacco users, mild, moderate and severe periodontitis was present in $20.0 \%, 35.4 \%$ and $44.6 \%$ respectively in the surveyed population (Table 3).

The factors which showed statistically significant association with periodontitis in multivariate analysis were age groups of the participants, smokers, khaini users, plaque accumulation and teeth loss. The table clearly illustrates that periodontitis increase with increasing age. Older age groups had an increased risk of having periodontitis $(\mathrm{OR}=7.58$ [95\% CI 3.93-14.61]), when compared to younger age groups. A statistically significant association was also found between tobacco users (smokers and khaini users) and periodontitis.
Logistic regression has shown that when compared to non-smokers, cigarette/bidi smoking had an increased risk for developing periodontitis $(\mathrm{OR}=3.14$ [95\% CI 1.36-7.27]). Similarly, the use of smokeless tobacco in the form of khaini (OR $=2.27$ [95\% CI 1.12-4.61]) had an increased risk for having periodontitis when compared to adults who never used khaini. Increased prevalence of periodontitis was also reflected in participants with increased tooth mortality, and the association was statistically significant $(\mathrm{OR}=2.02$ [95\% CI 1.21-3.38]). Plaque accumulation also showed a statistically significant association with the prevalence of periodontitis, but, with a low odds ratio $(\mathrm{OR}=1.01$ [95\% CI 1.00-1.02]). The number of males in our study were low, however they had a higher prevalence of periodontal tissue loss $(\mathrm{OR}=1.37$ [95\% CI 0.75-2.48]). Participants with poor oral hygiene, $(\mathrm{OR}=1.86[95 \% \mathrm{CI}=0.77-4.51])$, had increased risk of developing periodontitis when compared to participants with good oral hygiene, but this was not significant at multivariable level. Factors such as the socio-economic status, brushing frequency, and smokeless tobacco chewers did not show a significant association with periodontitis when adjusted for other factors at both univariate and multivariate analysis (Table 4).

\section{Discussion}

In the presented study, the overall prevalence of periodontitis was found to be $71.6 \%$. Subjects of Asian ethnicity are known to have the third-highest prevalence of periodontitis [26]. Surveys conducted in India, Nepal, and Vietnam have also reported, one-third to half of the middle-age population, are affected with periodontitis [27]. However, the case-based definition used for periodontitis varies from study to study, and identifying the true prevalence of periodontitis continues to be a challenge. Despite this, the prevalence of periodontitis is high in the surveyed population and the factors responsible are poor oral hygiene, presence of plaque along with tobacco consumption rather than gender, geography or economic status.

Periodontitis is a multifactorial disease that may be modifiable or non-modifiable [28]. Our study identified tobacco smoking, smokeless tobacco in the form of khaini and other factors such as age, plaque accumulation and teeth loss as significant factors associated with periodontitis. Similar findings have been reported by Bhat et al. in 2018 [29] who concluded that sociodemographic factors such as age, plaque, and tobacco are the main risk indicators to periodontitis in a rural Indian population. Age has been described as a non-modifiable predisposing factor, and with ample of epidemiological evidence [30,31] suggesting it, this study further adds to evidence that the periodontitis tends to cumulate for life. 
Table 4 Univariate and multivariate logistic regression analysis between tobacco use and other factors with periodontitis

\begin{tabular}{|c|c|c|c|c|c|c|}
\hline & Periodontitis present & $\mathrm{COR}^{\mathrm{a}}$ & p value & $\mathrm{AOR}^{\mathrm{b}}$ & $95 \% \mathrm{Cl}(\mathrm{L}-\mathrm{U})$ & $p$ value \\
\hline \multicolumn{7}{|l|}{ Age groups } \\
\hline $20-35$ & $47(42.7 \%)$ & Constant & $<0.001$ & Constant & & \\
\hline $35-44$ & $80(64.5 \%)$ & 2.43 & & 1.98 & $1.12-3.49$ & $<0.018$ \\
\hline $45-65$ & $188(91.3 \%)$ & 14.00 & & 7.58 & $3.93-14.61$ & $<0.001$ \\
\hline \multicolumn{7}{|l|}{ Gender } \\
\hline Female & $163(64.2 \%)$ & Constant & $<0.001$ & Constant & & \\
\hline Male & $152(81.7 \%)$ & 2.49 & & 1.37 & $0.75-2.48$ & NS \\
\hline \multicolumn{7}{|l|}{ SES } \\
\hline Upper & $14(87.5 \%)$ & 3.08 & 0.363 & - & & \\
\hline Lower middle & $122(73.5 \%)$ & 1.22 & & & & \\
\hline Lower & $179(69.4 \%)$ & Constant & & & & \\
\hline \multicolumn{7}{|c|}{ Brushing frequency } \\
\hline$\leq$ Once/day & $229(73.4 \%)$ & Constant & 0.190 & Constant & & \\
\hline$\geq$ Twice/day & $86(67.2 \%)$ & 1.34 & & 1.19 & $0.68-2.06$ & NS \\
\hline \multicolumn{7}{|l|}{$\mathrm{OHI}-\mathrm{S}$} \\
\hline Good & $34(50.7 \%)$ & Constant & $<0.001$ & Constant & & \\
\hline Fair & $133(65.8 \%)$ & 1.87 & & 1.01 & $0.50-2.01$ & NS \\
\hline Poor & $148(86.5 \%)$ & 6.24 & & 1.86 & $0.77-4.51$ & NS \\
\hline \multicolumn{7}{|l|}{ Missing teeth } \\
\hline Absent & $134(60.4 \%)$ & Constant & $<0.000$ & Constant & & \\
\hline Present & $181(83.0 \%)$ & 3.21 & & 2.02 & $1.21-3.38$ & 0.007 \\
\hline \multicolumn{7}{|l|}{ Smoking status } \\
\hline Absent & 232 (66.5\%) & Constant & $<0.001$ & Constant & & \\
\hline Present & $83(91.2 \%)$ & 5.23 & & 3.14 & $1.36-7.27$ & 0.007 \\
\hline \multicolumn{7}{|l|}{ Khaini } \\
\hline Absent & $226(66.7 \%)$ & Constant & $<0.001$ & Constant & & \\
\hline Present & 89 (88.1\%) & 3.70 & & 2.27 & $1.12-4.61$ & 0.023 \\
\hline \multicolumn{7}{|l|}{ SLT chewers } \\
\hline Absent & 277 (71.2\%) & Constant & 0.623 & - & & \\
\hline Present & $38(74.5 \%)$ & 1.18 & & & & \\
\hline BMI & $24.6+2.6$ & 1.23 & $<0.001$ & 1.07 & $0.96-1.19$ & NS \\
\hline PLI & $71.9+20.2$ & 1.03 & $<0.001$ & 1.01 & $1.00-1.02$ & 0.004 \\
\hline BPI & $49.7+24.4$ & 1.02 & $<0.001$ & 1.00 & $0.99-1.02$ & NS \\
\hline
\end{tabular}

a Crude odds ratio

b Adjusted odds ratio

Plaque is considered the primary etiological factor for periodontitis [32], and it's also a preventable factor that forms the basis for management of periodontitis. In this study, over $90 \%$ of the population answered that they use a toothbrush to clean their teeth at least one time daily. However, plaque accumulation showed significant association with periodontitis in the assessed population. The number of lost teeth in adults has also been used as a marker for periodontitis in the epidemiologic literature $[33,34]$. Our study showed a two-fold increase in the trend of teeth loss, and this could be attributed to periodontal reasons (loss of attachment), presence of dental caries and tobacco use.
This study is one of the few cross-sectional surveys conducted to document the impact of smoking and smokeless tobacco in alternative forms on the periodontium in a rural adult Nepalese population. The influence of tobacco smoking has been studied extensively and has been implicated as one of the important risk factors to periodontitis $[35,36]$. The prevalence of tobacco smoking was $20.7 \%$ in our study and the results are in accordance with the STEPS survey done in 2012-2013 amongst the Nepalese population [37]. An almost two to four-fold increased risk of developing periodontitis is attributable to smoking as compared with adults who never smoke [38-40]. The current study also showed cigarette smokers 
to have a three-fold increase in risk for periodontitis than non-smokers. There is a growing perception that SLT use is relatively safer than cigarette smoking and may be an alternative to tobacco smoking [41]. In our study, 83.5\% of the population using SLT in both forms had periodontitis. Studies conducted in districts of Karnataka, India and NHANES III survey representing the U.S population, reported a nearly two-fold increase in risk for periodontitis among SLT users [15, 42]. Nepal STEPS survey reveals khaini to be the most common SLT product used followed by chewing tobacco [43]. Our study concluded that participants consuming khaini $(66.4 \%$ of adults in our study consumed SLT in the form of khaini) were almost twice as likely to develop periodontitis compared to the participants who never used khaini. The results of this study are in agreement to a hospital-based study done in India by Katuri et al. in 2016 [44] which showed the most commonly used SLT product as khaini and concluded SLT users to have greater attachment loss. Similarly, studies done by Kulkarni et al. [21] and Kathiriya et al. [45] in 2016 reported gutkha and khaini to be the most commonly used products, and identified SLT to have similar impact on periodontium as tobacco smoke. In countries like India and Nepal, over 90\% of SLT users use tobacco as the main constituent or often betel quid, slaked lime, catechu are added to tobacco [46]. Therefore, nicotine exposure may exert a wide range of effects on the periodontal tissues. Traditional khaini available in south east Asian countries has a high $\mathrm{pH}$ and nicotine content, that may facilitate rapid absorption of chemicals through oral mucosa making the population more susceptible to periodontitis [11]. Few researchers have also reported a strong association between SLT chewers and periodontal diseases [47, 48]. However, our study, showed no statistically significant association between SLT chewers and periodontitis. The exact reason for the decrease in periodontitis in SLT chewers is unknown; but one explanation could be, that unlike traditional khaini, which is placed in-between the teeth and gums and sucked slowly over time, chewing SLT builds and mixes with the saliva to form a juice, that is either spat out or swallowed, exerting a lesser effect of harmful chemicals on the periodontium [49]. Variations in the effects of SLT products in relation to periodontium exist across the globe and, therefore, the results should be interpreted based on population studied. However, it would be fair to predict that due to pervasive use of SLT, periodontitis will be higher than projected and this study indicates that SLT in the form of khaini had a significant generalized periodontal involvement.

The limitations of the study include that only those participants who attended the dental health camps were examined and thus, it may not be a complete representation of the population. Also, the study faced serious constraints in terms of resources, lack of additional experts and time, as single-day health camps were organized in different wards. Therefore, studies in a large number of populations in the community are needed to further validate the impact of different forms of tobacco products on the periodontium.

\section{Conclusion}

Periodontitis is prevalent in the surveyed Nepalese population. The findings contribute to the evidence of smoking along with smokeless tobacco in the form of khaini as significant factors associated with periodontitis.

\section{Supplementary Information}

The online version contains supplementary material available at https://doi. org/10.1186/s12903-021-01416-3.

Additional file 1. Pre-tested semi-structured questionnaire.

Abbreviations

AOR: Adjusted odds ratio; BMI: Body mass index; BPI: Bleeding point index; COR: Crudes odds ratio; CAL: Clinical attachment loss; CDC-AAP: Center for disease control-American academy of periodontology; CEJ: Cemento-enamel junction; NS: Not significant; OHI-S: Simplified oral hygiene index; PD: Probing depth; PLI: Plaque index; SES: Socio-economic status; SD: Standard deviation; SLT: Smokeless tobacco; TLPD: Tooth loss due to periodontal disease; UNC-15: University of North Carolina-15.

\section{Acknowledgements}

Not applicable.

\section{Authors' contributions}

KG conceived, conceptualized and designed the study. KG collected the data and drafted the manuscript. SS critically revised the manuscript for important intellectual content, and approved the final version to be published. DDB analyzed and interpreted the data. SKA provided valuable comments on biostatistics and organized the community dental health camps. All authors read and approved the final manuscript.

Funding

No funding.

Availability of data and materials

The datasets supporting the findings of this article are available from the corresponding author.

\section{Ethics approval and consent to participate}

This study was approved by the Institutional Review Committee (IRC) of B.P Koirala Institute of Health Sciences, Dharan, Nepal (Ref. No. 472/073/074-IRC; Code no.: IRC/0959/017). Written consent was obtained from each participant after explaining the objectives of the study.

Consent for publication

Not applicable.

Competing interests

The authors declare that they have no competing interests. 


\begin{abstract}
Author details
${ }^{1}$ Department of Periodontology and Oral Implantology, College of Dental Surgery, B.P Koirala Institute of Health and Sciences, Dharan 56700, Nepal. 2 School of Public Health and Community Medicine, B.P Koirala Institute of Health and Sciences, Dharan 56700, Nepal. ${ }^{3}$ Department of Public Health Dentistry, College of Dental Surgery, B.P Koirala Institute of Health and Sciences, Dharan 56700, Nepal.
\end{abstract}

Received: 27 March 2020 Accepted: 28 January 2021

Published online: 12 February 2021

\section{References}

1. Anand PS, Kamath KP, Nair B. Trends in extraction of permanent teeth in private dental practices in Kerala State, India. J Contemp Dent Pract. 2010;11(3):041-8.

2. Sanz M, D'aiuto F, Deanfield J, et al. European workshop in periodontal health and cardiovascular disease-scientific evidence on the association between periodontal and cardiovascular diseases: a review of the literature. Eur Heart J Suppl. 2010;12(suppl_B):B3-12.

3. Kassebaum NJ, Bernabe E, Dahiya M, et al. Global burden of severe periodontitis in 1990-2010: a systematic review and meta-regression. J Dent Res. 2014:93(11):1045-53.

4. Genco RJ, Borgnakke WS. Risk factors for periodontal disease. Periodontology. 2013;62(1):59-94.

5. Holtfreter B, Albandar JM, Dietrich T, et al. Standards for reporting chronic periodontitis prevalence and severity in epidemiologic studies: proposed standards from the Joint EU/USA Periodontal Epidemiology Working Group. J Clin Periodontol. 2015;42(5):407-12.

6. Bergstrom J, Eliasson S. Cigarette smoking and alveolar bone height in subjects with a high standard of oral hygiene. J Clin Periodontol. 1987;14(8):466-9.

7. Rosa GM, Lucas GQ, Lucas ON. Cigarette smoking and alveolar bone in young adults: a study using digitized radiographs. J Periodontol. 2008;79(2):232-44.

8. Benjamin RM. Exposure to tobacco smoke causes immediate damage: a report of the surgeon general. Public Health Rep. 2011;126(2):158-9.

9. Chu YH, Tatakis DN, Wee AG. Smokeless tobacco use and periodontal health in a rural male population. J Periodontol. 2010;81(6):848-54.

10. Gupta B, Johnson NW. Systematic review and meta-analysis of association of smokeless tobacco and of betel quid without tobacco with incidence of oral cancer in South Asia and the Pacific. PLoS ONE. 2014:9(11):e113385

11. Stanfill SB, Connolly GN, Zhang L, et al. Global surveillance of oral tobacco products: total nicotine, unionised nicotine and tobacco-specific N-nitrosamines. Tob Control. 2011;20(3):e2.

12. Mukherjea A, Morgan PA, Snowden LR, et al. Social and cultural influences on tobacco-related health disparities among South Asians in the USA. Tob Control. 2012;21(4):422-8.

13. Giovino GA, Mirza SA, Samet JM, et al. Tobacco use in 3 billion individuals from 16 countries: an analysis of nationally representative cross-sectional household surveys. Lancet. 2012;380(9842):668-79.

14. Robertson PB, Walsh M, Greene J, et al. Periodontal effects associated with the use of smokeless tobacco. J Periodontol. 1990;61(7):438-43.

15. Fisher MA, Taylor GW, Tilashalski KR. Smokeless tobacco and severe active periodontal disease. NHANES III J Dent Res. 2005:84(8):705-10.

16. Montén U, Wennström JL, Ramberg P. Periodontal conditions in male adolescents using smokeless tobacco (moist snuff). J Clin Periodontol. 2006;33(12):863-8.

17. Department of Health Services. National Oral Health Policy 2014. Kathmandu: Oral Health Focal Point, Management Division, Department of Health Services; 2014

18. Gupta PC, Ray CS. Smokeless tobacco and health in India and South Asia. Respirology. 2003;8(4):419-31

19. https://cbs.gov.np/wp-content/upLoads/2019/05/District\%20Profile\%20 of\%20Sunsari\%202074.pdf

20. Ghosh A, Ghosh T. Modification of Kuppuswamy's Socioeconomic Status Scale in context to Nepal. Indian Pediatr. 2009;46:1104-5.
21. Kulkarni V, Uttamani JR, Bhatavadekar NB. Comparison of clinical periodontal status among habitual smokeless-tobacco users and cigarette smokers. Int Dent J. 2016;66(1):29-35.

22. O'Leary TJ. The periodontal screening examination. J Periodontol. 1967;38:617-24.

23. Lennox JA, Kopczyk RA. A clinical system for scoring a patient's oral hygiene performance. J Am Dent Assoc. 1973;86:849-52.

24. Greene JC, Vermillion JR. The simplified oral hygiene index. J Am Dent Assoc. 1964:68:7-13.

25. Eke PI, Page RC, Wei L, et al. Background: update of the case definitions for population-based surveillance of periodontitis. J Periodontol. 2012;83(12):1449-54

26. Albandar JM, Rams TE. Global epidemiology of periodontal diseases: an overview. Periodontology. 2000;2002(29):7-10.

27. Helderman W, Groeneveld A, Truin GJ, et al. Analysis of epidemiological data on oral diseases in Nepal and the need for a nationa oral health survey. Int Dent J. 1998;48(1):56-61.

28. Page RC, Krall EA, Martin J, et al. Validity and accuracy of a risk calculator in predicting periodontal disease. J Am Dent Assoc. 2002;133(5):569-76.

29. Bhat M, Do L, Roberts-Thomson K. Risk indicators for prevalence, extent and severity of periodontitis among rural Indian population aged 35-54 years. Int J Dent Hyg. 2018;16(4):492-502.

30. Abdellatif HM, Burt BA. An epidemiological investigation into the relative importance of age and oral hygiene status as determinants of periodontitis. J Dent Res. 1987:66(1):13-8.

31. Machtei EE, Dunford R, Grossi SG. Cumulative nature of periodontal attachment loss. J Periodont Res. 1994:29(5):361-4.

32. Corbet $E$, Davies W. The role of supragingival plaque in the control of progressive periodontal disease: a review. J Clin Periodontol. 1993;20(5):307-13.

33. Dietrich T, Walter C, Oluwagbemigun K, et al. Smoking, smoking cessation, and risk of tooth loss: the EPIC-Potsdam study. J Dent Res. 2015;94(10):1369-75.

34. Begum S, Reddy V, Kumar R, et al. Tooth loss prevalence and risk indicators among adult people visiting community health centers in Nellore district, Andhra Pradesh: a cross-sectional study. J Indian Assoc Public Health Dent. 2016;14:413-8.

35. Krall EA. Smoking, smoking cessation, and tooth loss. J Dent Res. 1997;76(10):1653-9.

36. Haber J, Wattles J, Crowley M, et al. Evidence for cigarette smoking as a major risk factor for periodontitis. J Periodontol. 2010;64(1):16-23.

37. WHO report on the global tobacco epidemic, 2017, Nepal, conducted by $\mathrm{WHO}$ report on the global tobacco epidemic 2017 [internet]. Geneva: WHO; 2017. http://www.who.int/tobacco/global_report/en/. Accessed 2 Jan 2019

38. Hugoson A, Rolandsson M. Periodontal disease in relation to smoking and the use of Swedish snus: epidemiological studies covering 20 years (1983-2003). J Clin Periodontol. 2011;38(9):809-16.

39. de Araújo NM, Malo P. Prevalence of periodontitis, dental caries, and periimplant pathology and their relation with systemic status and smoking habits: results of an open-cohort study with 22009 patients in a private rehabilitation center. J Dent. 2017;67:36-42.

40. Khan S, Khalid T, Awan KH. Chronic periodontitis and smoking: prevalence and dose-response relationship. Saudi Med J. 2016;37(8):889-94.

41. Liu ST, Nemeth JM, Klein EG, et al. Risk perceptions of smokeless tobacco among adolescent and adult users and nonusers. J Health Commun. 2015;20(5):599-606

42. Mohamed S, Janakiram C. Periodontal status among tobacco users in Karnataka. India Indian J Public Health. 2013;57(2):105-8.

43. Aryal KK, Neupane S, Mehata S, et al. Non communicable diseases risk factors: STEPS Survey Nepal 2013. Kathmandu: Nepal Health Research Council; 2014.

44. Katuri KK, Alluri JK, Chintagunta C, et al. Assessment of periodontal health status in smokers and smokeless tobacco users: a cross-sectional study. J Clin Diagnostic Res. 2016;10(10):ZC143-6.

45. Dinta K, Murali R, Madhusudan K, et al. Assessment of periodontal status in smokeless tobacco chewers and nonchewers among industrial workers in North Bengaluru. J Indian Assoc Public Health Dent. 2016;14(4):383-8.

46. EU Working Group on Tobacco and Oral Health. Meeting Report. Oral Dis. 1998:4:464-7. 
47. Sumanth SS, Bhat KM, Bhat GS. Periodontal health status in pan chewers with or without the use of tobacco. Oral Heal Prev Dent. 2008;6(3):223-9.

48. Javed F, Altamash M, Klinge B, et al. Periodontal conditions and oral symptoms in gutka-chewers with and without type 2 diabetes. Acta Odontol Scand. 2008;66:268-73.

49. Sinha DN, Bajracharya BKB, et al. Smokeless tobacco use in Nepal. Indian J Cancer. 2012:49(4):352-6.

\section{Publisher's Note}

Springer Nature remains neutral with regard to jurisdictional claims in published maps and institutional affiliations.
Ready to submit your research? Choose BMC and benefit from:

- fast, convenient online submission

- thorough peer review by experienced researchers in your field

- rapid publication on acceptance

- support for research data, including large and complex data types

- gold Open Access which fosters wider collaboration and increased citations

- maximum visibility for your research: over $100 \mathrm{M}$ website views per year

At BMC, research is always in progress.

Learn more biomedcentral.com/submissions 